\title{
Evaluation of Fermented Sausages Manufactured with Reduced-fat and Functional Starter Cultures on Physicochemical, Functional and Flavor Characteristics
}

\author{
Young Joo Kim, Sung Yong Park, Hong Cheol Lee, Seung Seok Yoo', Se Jong Oh, \\ Hyeong Sang Kim, and Koo Bok Chin* \\ Department of Animal Science and Functional Foods Research Institute, \\ Chonnam National University, Gwangju 500-757, Korea \\ ${ }^{1}$ Department of Culinary and Foodservice Management, Sejong University, Seoul 143-747, Korea
}

\begin{abstract}
Fermented foods with probiotics having functional properties may provide beneficial effects on health. These effects are varied, depending on the type of lactic acid bacteria (LAB). Different probiotic LAB might have different functional properties. Thus, this study was performed to evaluate the quality of fermented sausages manufactured with functional starter cultures (Lactobacillus plantarum 115 and 167, and Pediococcus damnosus L12) and different fat levels, and to determine the optimum condition for the manufacture of these products. Medium-fat $(\sim 15 \%)$ fermented sausages reduced the drying time and cholesterol contents, as compared to regular-fat counterparts. In proximate analysis, the contents of moisture and protein of regular-fat products were lower than medium-fat with reduced fat content. The regular-fat products also had a lighter color and less redness, due to reduced fat content. Approximately 35 volatile compounds were identified in functional fermented sausages, and hexanal, trans-caryophyllene, and tetradecanal were the major volatile compounds. Selected mixed starter culture showed the potential possibility of replacing the commercial starter culture (LK30 plus) in flavor profiles. However, medium-fat fermented sausage containing selected mixed starter culture tended to be less acceptable than their high-fat counterparts, due to excess dry ring developed in the surface. These results indicate that the use of combinations of L. plantarum 115 and 167, and P. damnosus L12 as a starter culture, will prove useful for manufacturing the fermented sausage.
\end{abstract}

Key words: fermented sausages, different fat levels, functional starter culture, volatile compounds

\section{Introduction}

Recently, consumers tend to prefer functional foods associated with "well-being" due to increase of health-concern (Kim, 2004). Thus, consumers tended to avoid the foods containing high fat, which causes to obesity, arteriosclerosis and hypertension. Especially, fermented sausages contained fat more than $30 \%$, and their fat contents were increased by moisture loss during fermentation and drying procedure. Fat in fermented sausage contributes to textural properties, and is a precursor of various flavor compounds and produces aldehydes, ketones and shortchain fatty acids, which significantly contributes to flavor

*Corresponding author: Koo Bok Chin, Department of Animal Science and Functional Foods Research Institute, Chonnam National University, Gwangju 500-757, Korea. Tel: +82-62-5302121, Fax:+82-62-530-2129, E-mail: kbchin@chonnam.ac.kr profile of fermented sausage (Lücke, 1985). Recently, many studies have been conducted to develop low-fat or reduced-fat fermented sausage without flavor and textural defects (Campagnol et al., 2012; Lorenzo and Franco, 2012; Olivares et al., 2010; Ruiz-Capillas et al., 2012). Papadima and Bloukas (1999) studied effect of fat level (10, 20 and $30 \%$ ) and storage conditions on quality characteristics of traditional Greek sausages, and reported that fermented sausage including $20 \%$ fat had the highest sensory attributes of three fat levels. In addition, Mendoza et al. (2001) reported that low-fat fermented sausage manufactured with inulin as fat substitute had the highest acceptability in sensory factors such as texture, tenderness, adhesiveness and springiness. According to Muguerza et al. (2002) who studied effect of fat level and partial replacement of pork back fat with olive oil on processing and quality characteristics of fermented sausages, $20 \%$ of fat level can be replaced with pre-emulsified mixture of 
olive oil and soy protein isolate. Lorenzo and Franco (2012) reported that the fat level affected the color and texture at the end of processing and individual free fatty acids as followed this order: oleic, palmitic, linoleic and stearic acid representing $82-95 \%$ of the total free fatty acids. This free fatty acid also contributed to the flavor compounds, such as 2-heptanal, methylester of heptanoic, pentanoic and hexanoic acid which might be consider as a marker compounds of flavor (Lorenzo et al., 2013).

Also, many studies have been widely performed to evaluate functionality of lactic acid bacteria (LAB) isolated from fermented sausages (De Vuyst et al., 2008). pH values of fermented sausages are decreased because of lactic acid produced by LAB. As a result, undesirable microbial growth is inhibited, and these fermented sausages have sourish taste during ripening. Among studies related to LAB, Erkkila et al. (2001) manufactured dry sausage using Lactobacillus rhamnosus strains as starter cultures, and found that L. rhamnosus strains were suitable for probiotic starter cultures. Also, Papamanoli et al. (2003), who isolated lactic acid bacteria having antimicrobial activity from traditional fermented sausage, reported that $L$. sakei, L. curvatus and L. plantarum strains had growth inhibition effects of Staphylococcus aureus. Similar result was reported by Kaban and Kaya (2006). They found that starter A (Pseudomonas acidilactici + L. curvatus $+S$. xylosus) or starter B (L. sakei + S. carnosus) added to fermented sausages significantly inhibited the growth of $S$. aureus during ripening procedure. According to the results of Urso et al. (2006) studied L. sakei separated from spontaneous fermented sausages, fermented sausages with $L$. sakei had higher acceptability than those with commercial starter culture. Finally, fermented foods with LAB having functional properties may provide beneficial effects in health, such as cholesterol assimilation and angiotension converting enzyme (ACE) inhibitory activity (Lücke, 2000).

Therefore, the objectives of this study were to assess the characteristics of fermented sausages manufactured with regular- or reduced-fat contents and to estimate the functionality of lactic acid bacteria having anti-cholesterol, anti-hypertension and anti-microbial activity on the fermented sausages.

\section{Materials and Methods}

\section{Materials}

Fresh whole pork hams were purchased from a wholesale meat market, trimmed out external excess fats and all connective tissue, and cut into a cubic inch. Cubic hams and trimmed back fat were vacuum-packaged and kept frozen at $-20^{\circ} \mathrm{C}$ for $2 \mathrm{wk}$ to inactivate Trichinella spralis. After $2 \mathrm{wk}$, frozen pork back fats were thawed at $4^{\circ} \mathrm{C}$ for $24 \mathrm{~h}$ and ground (M-12s, Hankook Fujee Plant Industries Co., Ltd., Korea) through a 3-4 $\mathrm{mm}$ plate, after which were kept at $-5^{\circ} \mathrm{C}$ for $24 \mathrm{~h}$ prior to use. Probiotic starter cultures having cholesterol assimilation, angiotensin Iconverting enzyme (ACE) inhibitory activity and antimicrobial activities (L. plantarum $\mathrm{L} 155+L$. plantarum $\mathrm{L} 167+$ P. damnosus L12) were isolated from Kimchi, and compared to the commercial one (LK-30 plus, Gewürzmüller Co., Germany) as described in previous report (Han et al., 2006).

\section{Fermented sausage formulation and processing}

Regular-fat $(\sim 30 \%)$ fermented sausages were manufactured according to the following formulation; pork lean $(70 \%)$, back fat (30\%), $\mathrm{NaCl}(2.5 \%)$, Glucono-delta-lactone $(0.7 \%), \mathrm{NaNO}_{2}(0.02 \%), \mathrm{NaNO}_{3}(0.015 \%)$, white pepper $(0.3 \%)$, ascorbic acid $(0.1 \%)$, coriander $(0.05 \%)$ and probiotic starter cultures or LK-30 plus. Fat content of medium-fat fermented sausages were reduced to a half $(15 \%)$ of fat content of regular-fat fermented sausage. Probiotic starter cultures (L. plantarum L155 + L. plantarum L167 + P. damnosus L12) and LK-30 plus (Gewürzmüller Co., Germany) were added as starter culture in treatment and in control, respectively. The starter cultures were inoculated into fermented sausage as levels of 5-6 Log CFU/g.

Cubic ham muscles, back fats, ingredients and starter cultures were mixed using silent cutter (K-15, Talsa, Xirivella, EU) for $1 \mathrm{~min}$, and the mixtures were vacuumpackaged for air elimination, stuffed into fibrous casings (diameter, $4.5 \mathrm{~cm}$ ), dried and ripened in ripening chamber (H\&E, Myung Technology, Korea) as described by Chin et al. (1991). Then, the temperature and relative humidity $(\mathrm{RH})$ for $3 \mathrm{~d}$ of fermentation procedures were gradually reduced from 22 to $21^{\circ} \mathrm{C}$ and 93 and $90 \%$, respectively. After fermentation, fermented sausages were smoked at $<$ $40^{\circ} \mathrm{C}$ for $1 \mathrm{~h}$ in smoke chamber (NU-vu, ES-13, Food System, USA). After smoking, fermented sausages were moved into ripening chamber, and ripened under conditions of $15^{\circ} \mathrm{C}$ and $\mathrm{RH} 80 \%$ for approximately $18 \mathrm{~d}$ as previously described (Kim et al., 2008). Quality characteristics of fermented sausages were evaluated in $0,2,3,7$, 14 , and $21 \mathrm{~d}$.

\section{pH and proximate analysis}

$\mathrm{pH}$ values of sausage samples were measured by a $\mathrm{pH}$ 
meter (Mettler Toledo, Model 120, Switzerland). Moisture, fat and protein contents were analyzed using the dry oven $\left(102^{\circ} \mathrm{C}, 16 \mathrm{~h}\right)$ method, Soxhlet extraction and protein determination (BUCHI, Kjeltec Auto System, B-322, Switzerland), respectively, according to the AOAC (1995) methods.

Hunter color, shear force $(\mathrm{kgf} / \mathrm{g})$ and weight loss (WL, \%)

Hunter $\mathrm{L}$, $\mathrm{a}$ and $\mathrm{b}$ values were determined using a Color Reader (CR-10, Minolta Corp., LTD, Japan), as indicators of lightness, redness and yellowness, respectively.

Allo-Kramer shear values $(\mathrm{kgf} / \mathrm{g})$ of fermented sausages were measured using Instron Universal Testing Machine (Model 3344, USA) equipped with multi blade Kramer shear attachment during ripening time. Ten samples per fermented sausage were made on individual sausage slices (5 mm thick) using a $500 \mathrm{~kg}$ load cell with $30 \mathrm{sec}$ down stroke over a shear load range of $100 \mathrm{~kg}$. The shear value was calculated as $\mathrm{kg}$ force $/ \mathrm{g}$ of surface area as followed by Park et al. (1991).

Weight loss was calculated according to method as follows:

Weight loss $(\%)=$

$\frac{(\text { Initial weight }(\mathrm{kg})-\text { weight after ripening }(\mathrm{kg}))}{\text { Initial weight }(\mathrm{kg})} \times 100$

\section{Microbial test}

Total plate count (TPC), de Man Rogosa Sharpe (MRS) and violet red bile (VRB) were used to determine total bacteria counts, lactic acid bacteria and Enterobacteriaceae, respectively. Homogenized samples $(10 \mathrm{~g})$ were mixed with $90 \mathrm{~mL}$ of sterile double deionized water (ddwater), and serial dilutions were prepared, then each dilution $(0.1 \mathrm{~mL})$ was spread in TPC, MRS and VRB agar. They were incubated at $37^{\circ} \mathrm{C}$ for $48 \mathrm{~h}$, counted and expressed as Log CFU/g. Antimicrobial activity of fermented sausages was evaluated by measuring the growth inhibition of Staphylococcus aureus which was inoculated at $10^{5-6} \mathrm{cells} / \mathrm{g}$ at the initial ripening.

\section{Cholesterol analyses and ACE inhibitory activities}

A $4 \mathrm{~mL}$-aliquots of fat extract were dried under nitrogen in a $60^{\circ} \mathrm{C}$ heat block. Fat residues were saponified with $10 \mathrm{~mL}$ of $15 \%$ alcoholic $\mathrm{KOH}$ (in $90 \%$ ethanol), and $5 \mathrm{~mL}$ of distilled water was added and allowed to cool to room temperature. The cholesterol contents were determined by method of Searcy and Bergquist (1960). ACE inhibitory activities of fermented sausages were followed by Cushman and Cheung (1971), respectively.

\section{Volatile compounds analysis}

Extraction of volatile compounds was performed by simultaneous distillation extraction (SDE) of Heath and Reineccius (1986). Quantitative and qualitative analysis of volatile compounds extracted from fermented sausages were performed according to method of Park et al. (2005).

\section{Statistical analysis}

The data were analyzed using two-way analysis of variance (ANOVA) in SPSS 12.0 software program, with factors for treatments and ripening time. Mean values of treatments (fat level and lactic acid combinations) were compared using the Duncan's multiple range test at the significance level (P) of 0.05 .

\section{Result and Discussion}

\section{Evaluation of physicochemical properties and mic- robiological changes of fermented sausages as affec- ted by fat content and ripening}

Since there was interaction between treatment and ripening time, data were pooled and listed by treatment (Table 1) and ripening time (Table 2). Chemical compositions, weight loss, lightness and redness values of fermented sausages were affected, whereas, $\mathrm{pH}$ and yellowness were not affected by fat content $(p>0.05)$ (Table 1). However, no differences in these parameters were observed by starter culture. Medium-fat ( $15 \%)$ fermented sausages had higher water and protein contents than regularfat $(\sim 33 \%)$ ones $(p<0.05)$. Higher weight loss was found in medium-fat fermented sausages as compared to regular-fat counterparts $(p<0.05)$. These results are in accordance with results of Papadima and Bloukas (1999) who reported that weight loss of fermented sausages increased with decreased fat levels. Also, medium-fat fermented sausages had higher redness values and lower lightness than regular-fat counterparts $(p<0.05)$. These results may partially due to nitrosylmyoglobin formed by reaction of myoglobin and nitrite. Total plate counts (TPC) and lactic acid bacteria (LAB) of regular-fat fermented sausages with LK-30 plus were lower than those of others $(p<0.05)$.

As shown in Table 2, $\mathrm{pH}$ values quickly decreased below 4.8 during the fermentation process, but tended to slowly increase after $6 \mathrm{~d}$ of ripening $(p<0.05)$. Moisture contents of fermented sausages decreased, whereas fat and protein contents increased with increased ripening time $(p<0.05)$. 
Table 1. Effects of fat content and various starter culture on $\mathrm{pH}$, Hunter color (L, a, b), proximate composition, bacterial counts (TPC, MRS) and weight loss (WL) of fermented sausages

\begin{tabular}{ccccc}
\hline \hline & \multicolumn{3}{c}{ Treatment $^{1}$} \\
\cline { 2 - 5 } & RFC & RFT & MFC & MFT \\
\hline pH & $4.96 \pm 0.26^{\mathrm{a}}$ & $4.93 \pm 0.32^{\mathrm{a}}$ & $4.98 \pm 0.29^{\mathrm{a}}$ & $5.02 \pm 0.36^{\mathrm{a}}$ \\
Moisture (\%) & $41.3 \pm 12.8^{\mathrm{b}}$ & $42.0 \pm 13.8^{\mathrm{b}}$ & $54.5 \pm 11.5^{\mathrm{a}}$ & $54.7 \pm 11.6^{\mathrm{a}}$ \\
Fat (\%) & $33.1 \pm 7.59^{\mathrm{a}}$ & $32.0 \pm 9.89^{\mathrm{a}}$ & $14.8 \pm 4.15^{\mathrm{b}}$ & $15.2 \pm 4.01^{\mathrm{b}}$ \\
Protein (\%) & $18.7 \pm 3.95^{\mathrm{c}}$ & $19.9 \pm 4.41^{\mathrm{b}}$ & $24.1 \pm 6.99^{\mathrm{a}}$ & $24.1 \pm 7.53^{\mathrm{a}}$ \\
WL (\%) & $17.3 \pm 12.4^{\mathrm{a}}$ & $17.9 \pm 13.0^{\mathrm{a}}$ & $20.1 \pm 15.4^{\mathrm{a}}$ & $20.1 \pm 15.8^{\mathrm{a}}$ \\
Hunter L & $63.9 \pm 4.10^{\mathrm{a}}$ & $63.8 \pm 4.47^{\mathrm{a}}$ & $57.2 \pm 2.56^{\mathrm{b}}$ & $57.6 \pm 2.62^{\mathrm{b}}$ \\
Hunter a & $11.9 \pm 1.46^{\mathrm{b}}$ & $12.0 \pm 1.50^{\mathrm{b}}$ & $14.2 \pm 2.59^{\mathrm{a}}$ & $14.2 \pm 1.99^{\mathrm{a}}$ \\
Hunter b & $7.27 \pm 1.68^{\mathrm{a}}$ & $7.07 \pm 2.23^{\mathrm{a}}$ & $7.79 \pm 1.52^{\mathrm{a}}$ & $7.45 \pm 1.58^{\mathrm{a}}$ \\
TPC (Log CFU/g) & $7.73 \pm 1.19^{\mathrm{b}}$ & $8.13 \pm 1.13^{\mathrm{a}}$ & $7.97 \pm 1.34^{\text {ab }}$ & $8.26 \pm 1.27^{\mathrm{a}}$ \\
MRS (Log CFU/g) & $7.53 \pm 1.22^{\mathrm{b}}$ & $8.08 \pm 1.20^{\mathrm{a}}$ & $7.86 \pm 1.40^{\mathrm{a}}$ & $8.18 \pm 1.32^{\mathrm{a}}$ \\
\hline
\end{tabular}

${ }^{\mathrm{a}, \mathrm{b}}$ Means with a same superscript within a same row are not different $(p>0.05)$.

${ }^{1}$ Treatment: RFC $=$ regular-fat $(\sim 30 \%)$ control $(\mathrm{LK} 30)$; RFT=regular-fat $(\sim 30 \%)$ treatment $(\mathrm{L} 155+\mathrm{L} 167+\mathrm{L} 12)$; MFC $=$ medium-fat $(\sim 15 \%)$ control (LK30); MFT=medium-fat (15\%) treatment $(\mathrm{L} 155+\mathrm{L} 167+\mathrm{L} 12) ;{ }^{2} \mathrm{TPC}=$ total plate count; ${ }^{3} \mathrm{MRS}=\mathrm{de}$ Man Rogosa Sharpe for lactic acid bacteria.

Table 2. Changes of $\mathrm{pH}$, proximate composition, Hunter color ( $\mathrm{L}, \mathrm{a}, \mathrm{b})$, bacterial counts and weight loss (WL) in medium-fat and regular-fat fermented sausages as affected by ripening time

\begin{tabular}{ccccccc}
\hline \hline & \multicolumn{7}{c}{ Ripening day } \\
\cline { 2 - 7 } & 0 & 2 & 3 & 6 & 14 & 21 \\
\hline pH & $5.52 \pm 0.17^{\mathrm{a}}$ & $4.82 \pm 0.10^{\mathrm{c}}$ & $4.71 \pm 0.07^{\mathrm{c}}$ & $4.81 \pm 0.06^{\mathrm{c}}$ & $4.99 \pm 0.15^{\mathrm{b}}$ & $4.97 \pm 0.06^{\mathrm{b}}$ \\
Moisture (\%) & $62.9 \pm 5.85^{\mathrm{a}}$ & - & - & $53.9 \pm 1.63^{\mathrm{b}}$ & $38.7 \pm 4.36^{\mathrm{c}}$ & $31.6 \pm 2.76^{\mathrm{d}}$ \\
Fat (\%) & $16.9 \pm 6.58^{\mathrm{c}}$ & - & - & $13.4 \pm 0.16^{\mathrm{c}}$ & $29.3 \pm 1.01^{\mathrm{b}}$ & $36.9 \pm 3.83^{\mathrm{a}}$ \\
Protein (\%) & $15.0 \pm 1.08^{\mathrm{d}}$ & - & - & $24.6 \pm 0.97^{\mathrm{b}}$ & $26.2 \pm 1.11^{\mathrm{a}}$ & $23.2 \pm 1.07^{\mathrm{c}}$ \\
M:P ratio & 4.19 & - & - & 2.19 & 1.48 & 1.36 \\
WL (\%) & - & $10.2 \pm 1.94^{\mathrm{e}}$ & $14.2 \pm 2.42^{\mathrm{d}}$ & $24.6 \pm 4.82^{\mathrm{c}}$ & $36.8 \pm 6.95^{\mathrm{a}}$ & $34.8 \pm 1.18^{\mathrm{b}}$ \\
Hunter L & $61.0 \pm 4.84^{\mathrm{a}}$ & $63.0 \pm 4.98^{\mathrm{a}}$ & $63.6 \pm 4.36^{\mathrm{a}}$ & $60.9 \pm 5.10^{\mathrm{a}}$ & $58.0 \pm 3.91^{\mathrm{b}}$ & $57.4 \pm 1.68^{\mathrm{b}}$ \\
Hunter a & $10.5 \pm 1.77^{\mathrm{b}}$ & $13.6 \pm 1.15^{\mathrm{a}}$ & $13.5 \pm 1.66^{\mathrm{a}}$ & $14.3 \pm 2.04^{\mathrm{a}}$ & $13.8 \pm 1.76^{\mathrm{a}}$ & $11.3 \pm 2.16^{\mathrm{b}}$ \\
Hunter b & $10.2 \pm 0.73^{\mathrm{a}}$ & $7.86 \pm 0.78^{\mathrm{b}}$ & $7.22 \pm 0.88^{\mathrm{bc}}$ & $6.78 \pm 0.53^{\mathrm{bc}}$ & $6.09 \pm 0.62^{\mathrm{c}}$ & $4.93 \pm 1.84^{\mathrm{d}}$ \\
$\mathrm{TPC}^{2}(\log$ CFU/g) & $5.62 \pm 0.32^{\mathrm{c}}$ & $8.48 \pm 0.39^{\mathrm{ab}}$ & $8.66 \pm 0.32^{\mathrm{a}}$ & $8.77 \pm 0.26^{\mathrm{a}}$ & $8.44 \pm .035^{\mathrm{ab}}$ & $8.24 \pm 0.52^{\mathrm{b}}$ \\
$\mathrm{MRS}^{3}$ (Log CFU/g) & $5.41 \pm 0.40^{\mathrm{b}}$ & $8.36 \pm 0.49^{\mathrm{a}}$ & $8.34 \pm 0.50^{\mathrm{a}}$ & $8.67 \pm 0.27^{\mathrm{a}}$ & $8.53 \pm 0.35^{\mathrm{a}}$ & $8.26 \pm 0.50^{\mathrm{a}}$ \\
\hline
\end{tabular}

${ }^{\mathrm{a}-\mathrm{e}}$ Means with same superscript within a same row are not different $(p>0.05)$.

${ }^{1} \mathrm{M}: \mathrm{P}$ ratio=moisture: protein ratio; ${ }^{2} \mathrm{TPC}=$ total plate count; ${ }^{3} \mathrm{MRS}=\mathrm{de}$ Man Rogosa for lactic acid bacteria.

M:P ratio of 1.6 that regarded as an end point of ripening achieved about $14 \mathrm{~d}$ of ripening. Weight loss of fermented sausages tended to increase during ripening $(p<0.05)$. Lightness and yellowness values decreased with increased ripening time $(p<0.05)$, whereas redness increased during $6 \mathrm{~d}$ of ripening, and decreased thereafter. These results are supported by those of Papadima and Bloukas (1999), who reported that redness values of the fermented sausage containing $10 \%$ fat decreased with oxidation of nitrosylmyoglobin after $7 \mathrm{~d}$ of ripening. Total plate counts (TPC) and lactic acid bacteria (LAB) significantly increased until the levels of $8 \mathrm{Log}$ CFU/g during fermentation, and thereafter, a number of TPC and LAB were maintained up to end of ripening.

Significant differences in shear force values of fermented sausages were observed at $14 \mathrm{~d}$ of ripening, in which shear force values of medium- and regular -fat fermented sausages ranged from 8.75 to $9.39 \mathrm{kgf} / \mathrm{g}$ and from 5.05 to $6.08 \mathrm{kgf} / \mathrm{g}$, respectively (Table 3). According to Muguerza et al. (2002), reduction of fat level in fermented meat products induced excess weight losses, resulted in increases of hardness and toughness. Thus, the increased shear values were observed with decreased fat levels $(p<0.05)$, whereas starter culture didn't affect the shear value.

Regular-fat fermented sausages had lower total plate counts as compared to those with probiotics (Fig. 1(A)) $(p<$ 0.05 ), however, the medium-fat sausages had similar total bacterial counts regardless of probiotics. This results indicated that the total bacterial counts were affected by the fat content. The microbial counts of Enterobacteriaceae, were not observed during ripening (data not shown). According to De Vries et al. (2006), transportation of fecal Enterobacteriaceae, coronary diseases and irritable bowel syndrome were decreased by intake of $L$. plantarum. 
Table 3. Changes of shear force value (kgf/g) in fermented sausages as affected by fat content and starter cultures during ripening

\begin{tabular}{cccc}
\hline \hline \multirow{2}{*}{ Treatment } & \multicolumn{3}{c}{ Ripening time (day) } \\
\cline { 2 - 4 } & 6 & 14 & 21 \\
\hline RFC & - & $5.05 \pm 1.01^{\mathrm{b}}$ & $6.23 \pm 0.04^{\mathrm{a}}$ \\
RFT & - & $6.05 \pm 0.79^{\mathrm{b}}$ & $8.03 \pm 0.90^{\mathrm{a}}$ \\
MFC & $5.20 \pm 0.68^{\mathrm{b}}$ & $8.75 \pm 0.02^{\mathrm{a}}$ & - \\
MFT & $4.83 \pm 0.82^{\mathrm{b}}$ & $9.39 \pm 0.09^{\mathrm{a}}$ & - \\
\hline
\end{tabular}

$\overline{\mathrm{a}, \mathrm{b}}$ Means with a same superscript within a same row are not different $(p>0.05)$.

Treatment $^{1}: \mathrm{RFC}=$ regular-fat control $(\mathrm{LK} 30)$; RFT=regular-fat treatment $(\mathrm{L} 155+\mathrm{L} 167+\mathrm{L} 12)$; $\mathrm{MFC}=$ medium-fat control $(\mathrm{LK} 30)$; $\mathrm{MFT}=$ medium-fat treatment $(\mathrm{L} 155+\mathrm{L} 167+\mathrm{L} 12)$.

However, in this study, a number of $S$. aureus injected into final fermented sausages were not affected by starter culture and storage time. This result was partially due to the addition of complicated system, such as sausage as compared to the simple model study, which inhibited the S. aureus in the previous study (Han et al., 2006). The other potential possibility was that the bacteriocin produced by probiotics was not strong enough. According to Kaban and Kaya (2006), growth of $S$. aureus in sucuk (Turkish dry-fermented sausage) during ripening time was inhibited with the addition of P. acidilactici and $L$. curvatus or S. xylosus, L. sakei and S. carnosus. Muthukumarasamy and Holley (2007) reported that levels of Escherichia coli O157:H7 injected into fermented sausages were reduced when micro-encapsulated probiotics were added into fermented sausages. Also, Papamanoli et al. (2003) revealed that LAB such as L. sakei, L. curvatus and L. plantarum isolated from Greek dry fermented sau-

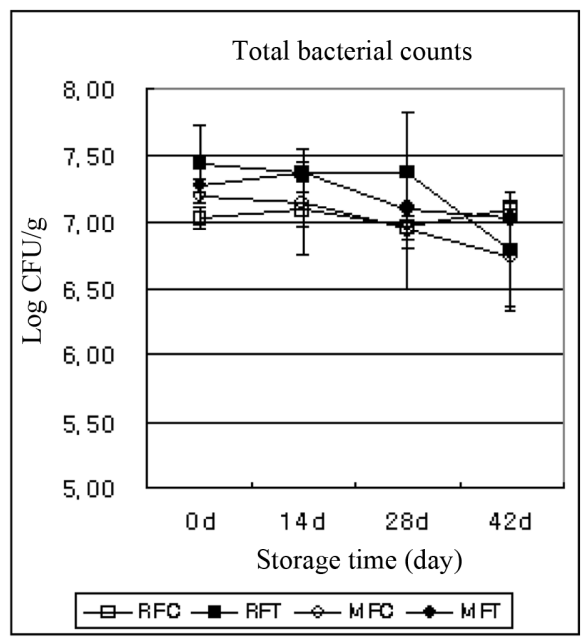

(A) sages inhibited the growth of $S$. aureus. In addition, Pennacchia et al. (2004) isolated Lactobacillus strain having probiotic properties from fermented sausages, and reported a use possibility of such $\mathrm{LAB}$ as new starter culture for manufacture of dry fermented sausages.

\section{Cholesterol analyses, ACE inhibitory activities and antimicrobial activity}

Functional properties, such as cholesterol assimilation and anti-hypertension of fermented sausages with probiotic starter culture, were determined (Table 4). ACE inhibitory activities were affected by starter cultures, and fermented sausages with selected starter culture showed higher ACE inhibition than counterparts, regardless of fat content $(p<0.05)$. However, cholesterol assimilation was not affected by starter culture. Cholesterol contents decreased with reduced fat content $(p<0.05)$ and significantly increased after $6 \mathrm{~d}$ of ripening time (Table 4). However, ACE inhibitory activities were not affected by ripening time ( $p>0.05)$. Leclerc et al. (2002) reported that ACE inhibitors were released from milk fermented by $L$. helveticus. Also, Pereira and Gibson (2002) and Gilliland and Walker (1990) reported that Bifidobacterium breve ATCC 15700 having cholesterol assimilation properties and L. acidophilus ATCC 43121 isolated from the intestinal tract of pig had potentiality as new functional lactic acid bacteria.

Change of volatile compounds in fermented sausage as affected by fat content and starter culture

The volatile compounds as affected by two different fat

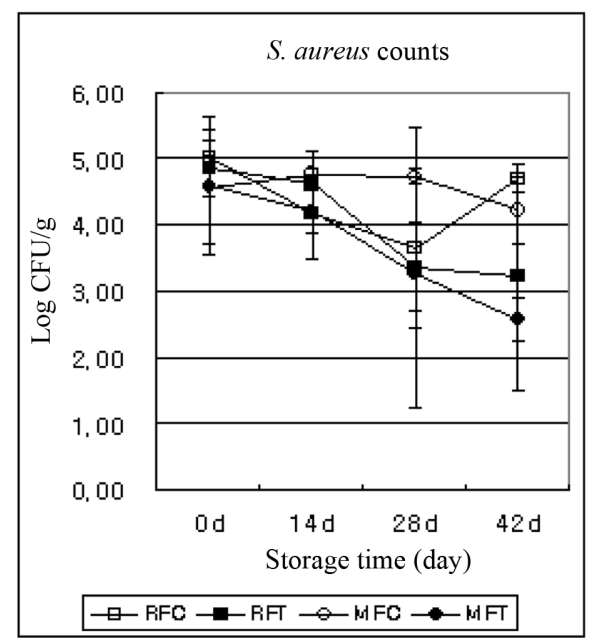

(B)

Fig. 1. Changes of total bacterial counts (Log CFU/g) and Staphylococcus aureus in fermented sausages as affected by fat content and starter culture during storage time. Treatment: RFS $=$ regular-fat control (LK 30) and regular-fat treatment (L155+L167+ L12); MFS=medium-fat control (LK 30) and medium-fat treatment (L155+L167+L12). 
Table 4. Evaluation of functional properties of fermented sausages as affected by starter culture, fat content and ripening time

\begin{tabular}{|c|c|c|c|c|c|c|}
\hline & \multicolumn{6}{|c|}{ Treatment } \\
\hline & RFC & \multicolumn{2}{|r|}{ RFT } & \multicolumn{2}{|l|}{ MFC } & MFT \\
\hline ACE inhibition (\%) & $15.6 \pm 2.88^{b}$ & \multicolumn{2}{|c|}{$17.8 \pm 1.74^{\mathrm{ab}}$} & \multicolumn{2}{|c|}{$15.7 \pm 2.65^{b}$} & $18.4 \pm 3.05^{\mathrm{a}}$ \\
\hline \multirow[t]{3}{*}{ Cholesterol (mg/100 g) } & $60.5 \pm 5.48^{\mathrm{a}}$ & \multicolumn{2}{|c|}{$59.8 \pm 6.02^{\mathrm{a}}$} & \multicolumn{2}{|c|}{$53.3 \pm 4.58^{\mathrm{b}}$} & $54.1 \pm 5.10^{\mathrm{b}}$ \\
\hline & \multicolumn{6}{|c|}{ Ripening time (day) } \\
\hline & 0 & 2 & 3 & 6 & 14 & 21 \\
\hline ACE inhibition (\%) & $15.5 \pm 2.80^{\mathrm{a}}$ & $17.9 \pm 2.44^{\mathrm{a}}$ & $18.4 \pm 2.36^{\mathrm{a}}$ & $17.4 \pm 2.59^{\mathrm{a}}$ & $17.4 \pm 3.09^{\mathrm{a}}$ & $14.8 \pm 2.62^{\mathrm{a}}$ \\
\hline Cholesterol $(\mathrm{mg} / 100 \mathrm{~g})$ & $56.4 \pm 2.76^{\mathrm{ab}}$ & $52.6 \pm 4.58^{\mathrm{b}}$ & $52.6 \pm 4.75^{\mathrm{b}}$ & $60.0 \pm 6.51^{\mathrm{a}}$ & $59.1 \pm 6.15^{\mathrm{a}}$ & $61.1 \pm 6.23^{\mathrm{a}}$ \\
\hline
\end{tabular}

${ }^{\mathrm{a}, \mathrm{b}}$ Means with a same superscript within a row are not different $(p>0.05)$.

Treatment $^{1}: \mathrm{RFC}=$ regular-fat control (LK 30); RFT=regular-fat treatment (L 155+L 167+L 12); MFC=medium-fat control (LK 30); MFT $=$ medium-fat treatment $(\mathrm{L} 155+\mathrm{L} 167+\mathrm{L} \mathrm{12})$

level and starter cultures are shown in Table 5. Total thirty-five volatile compounds were isolated and identified from regular- and medium-fat fermented sausage manufactured with LK30 plus or selected probiotic LAB (L. plantarum $\mathrm{L} 155+$ L. plantarum $\mathrm{L} 167+P$. damnosus L12) (Table 5). Among volatile compounds, hexanoic acid alone had interaction between treatments and ripening time $(p<0.05)$. In regular-fat fermented sausages, 2-pentyl-furan and 2-methoxy-4-methyl-phenol were affected by injected starter culture, and detected higher in RFC and RFT, respectively $(p<0.05)$. Since no differences in flavor profiles of medium-fat fermented sausages were observed between starter cultures added ( $p>0.05)$, except for hexanoic acid, selected probiotic starter culture showed the potential possibility to replace the commercial starter culture (LK30 plus) in flavor profiles. In RFC and MFC with same starter culture, hexanoic acid, 3,7-dimethyl-(E)1,3,6-octatriene and 3,4-dimethyl-3-cyclohexen-1-carboxaldehyde were affected by fat content, and detected higher in MFC, except for 3,7-dimethyl-(E)-1,3,6-octatriene ( $p<$ 0.05 ). Olivares et al. (2009) reported that the main volatile compounds were produced during lipid oxidation, resulting in generation of aldehydes and one unsaturated alcohol. And these indicated that the lipid acted as a substrate for oxidation reactions to form volatile compounds with flavor characteristics. In addition, phospholipid might be associated with the flavor development. Olivares et al. (2011) also reported that fat reduction decreased the generation of lipid derived volatile compounds during processing while those generation from bacterial metabolism increased.

\section{Change of volatile compounds in fermented sausage during ripening}

The volatile compounds produced during ripening were listed in Table 6. Among volatile compounds identified from regular- and medium-fat fermented sausages injected LK30 plus (L. sake + S. carnosus + M. varians) or selected probiotic starter culture (L. plantarum L155 + L. plantarum $\mathrm{L} 167+P$. damnosus L12), total nineteen volatile compounds were affected by ripening time, and increased with increased ripening time $(p<0.05)$ (Table 6). Among these compounds, 3-methyl-furan, 2-pentyl-furan, hexanoic acid, 2-methoxy-phenol, 1,3-benzodioxole-5-carboxaldehyde and 3,7-dimethyl-(E)-1,3,6-octatriene were not detected in initial ripening procedure, however, these compounds were detected in 3 or $7 \mathrm{~d}$ of ripening time. Tetradecanal, alpha-terpinolene and camphor were prominent volatile compounds at initial ripening time, and they possessed $53.7 \%$ of total volatile compounds identified. However, proportion of these compounds in final products reduced because they decreased with increased ripening time or tended to be maintained, and because other compounds such as hexanal, trans-caryophyllene, (E)-4tridecen-6-yne and (E)-5-eicosene remarkably increased. So, tetradecanal (170), alpha-terpinolene (105) and camphor (74.2) were prominent compounds at the initial ripening time, whereas alpha-terpinolene (351), trans-caryophyllene (223) and (E)-4-tridecen-6-yne (162) were prominent compounds at the end of ripening time, and they possessed $37.8 \%$ of total volatile compounds identified. Therefore, these volatile compounds might remarkably affect flavor profiles of final fermented sausages. Olivares et al. (2009) reported that 3-methyl butanal, 2-methyl butanaloctanal, diacetyl and ethyl 2-methylbutanoate were the predominant volatile compounds, however, propanal, petnal, hexanl, ethyl hexaonate and nonanal were the predominant flavor compounds in the end of ripening process. One year later (2010), they also reported that some consumer preferred high and medium-fat sausages with low ripening time, however, some consumer preferred sausages with high ripening time, regardless of fat 
Table 5. Changes of volatile compounds in fermented sausages with medium and regular-fat as affected by various starter cultures

\begin{tabular}{|c|c|c|c|c|c|}
\hline \multirow{2}{*}{ Compounds } & \multicolumn{5}{|c|}{ Treatment $^{1}$ (Relative area) } \\
\hline & RFC & RFT & MFC & MFT & SEM \\
\hline 3-hydroxy-2-butanone & 25.8 & 53.0 & 40.9 & 54.9 & 6.71 \\
\hline hexanal & 80.1 & 63.5 & 63.7 & 56.7 & 10.45 \\
\hline 3-methyl-furan & 11.9 & 20.4 & 32.5 & 23.7 & 4.77 \\
\hline 3-methyl-butanoic acid & 14.8 & 9.4 & 9.4 & 5.4 & 6.58 \\
\hline dimethyl trisulfide & 22.9 & 20.6 & 18.9 & 15.2 & 3.55 \\
\hline 2-pentyl-furan & $9.0^{\mathrm{a}}$ & $1.8^{\mathrm{b}}$ & $4.9^{\mathrm{ab}}$ & $3.6^{\mathrm{b}}$ & 1.45 \\
\hline$\gamma$-terpinene & 44.2 & 47.1 & 50.0 & 46.6 & 3.26 \\
\hline hexanoic acid & $5.3^{\mathrm{b}}$ & $6.0^{\mathrm{b}}$ & $7.3^{\mathrm{a}}$ & $5.6^{\mathrm{b}}$ & 0.44 \\
\hline 1-methyl-4-(1-methylethyl)-benzene & 9.6 & 22.6 & 4.1 & $\mathrm{t}^{1}$ & 8.05 \\
\hline $\mathrm{R}(+)$-limonen & 5.3 & 4.2 & 4.0 & 4.0 & 0.97 \\
\hline 1,3,5-cycloheptatriene & 1.0 & 1.1 & 5.1 & 3.4 & 1.74 \\
\hline 2-methoxy-phenol & 16.2 & 20.1 & 30.2 & 17.7 & 6.69 \\
\hline$\alpha$-terpinolene & 250.0 & 205.0 & 253.0 & 261.0 & 34.32 \\
\hline camphor & 108.0 & 105.0 & 78.0 & 56.7 & 18.25 \\
\hline 4-methyl-1-(1-methylethyl)-3-cyclohexen-1-ol & 11.9 & 6.0 & 6.0 & 4.7 & 2.38 \\
\hline 2-methoxy-4-methyl-phenol & $24.2^{\mathrm{b}}$ & $81.8^{\mathrm{a}}$ & $31.1^{\mathrm{b}}$ & $28.2^{\mathrm{b}}$ & 12.14 \\
\hline 4-ethyl-2-methoxy-phenol & 15.2 & 14.2 & 28.5 & 22.6 & 7.11 \\
\hline 1,3-benzodioxole-5-carboxaldehyde & 3.2 & 2.4 & 7.7 & 4.9 & 2.21 \\
\hline$\alpha$-copaene & 10.0 & 4.0 & 3.5 & 2.7 & 2.71 \\
\hline decanoic acid & 29.0 & 14.2 & 21.3 & 14.5 & 5.10 \\
\hline trans-caryophyllene & 158.0 & 140.0 & 116.0 & 87.5 & 29.08 \\
\hline 3,7-dimethyl-(E)-1,3,6-octatriene & $16.7^{\mathrm{a}}$ & $23.5^{\mathrm{a}}$ & $6.2^{\mathrm{b}}$ & $6.3^{\mathrm{b}}$ & 3.13 \\
\hline (E)-4-tridecen-6-yne & 97.9 & 110.0 & 139.0 & 120.0 & 19.94 \\
\hline caryophyllene oxide & 31.6 & 31.6 & 32.9 & 17.1 & 6.37 \\
\hline 3,4-dimethyl-3-cyclohexen-1-carboxaldehyde & $12.3^{\mathrm{c}}$ & $14.2^{\mathrm{bc}}$ & $25.5^{\mathrm{a}}$ & $19.9^{\mathrm{ab}}$ & 2.18 \\
\hline 4,8,8-trimethylspiro[2.6]non-4,6-diene & 3.9 & 2.9 & 12.9 & 10.3 & 3.78 \\
\hline adamantane & 2.9 & 1.5 & 6.4 & 5.2 & 3.11 \\
\hline 3,4-dimethyl-pyridine & 28.4 & 28.3 & 38.1 & 32.1 & 8.23 \\
\hline$\beta$-citronellol & 0.8 & 0.8 & 2.4 & 3.1 & 0.89 \\
\hline tetradecanoic acid & 62.1 & 65.7 & 63.6 & 48.5 & 13.79 \\
\hline tetradecanal & 115.0 & 136.0 & 205.0 & 191.0 & 42.35 \\
\hline octadecanal & 4.7 & 0.1 & 2.3 & 2.0 & 2.51 \\
\hline (E)-5-eicosene & 88.8 & 100.0 & 102.0 & 74.5 & 21.51 \\
\hline 1-hexadecanol & 9.9 & 9.4 & 23.4 & 19.4 & 5.86 \\
\hline n-hexadecanoic acid & 15.2 & 14.7 & 21.1 & 18.3 & 6.50 \\
\hline
\end{tabular}

${ }^{\mathrm{a}-\mathrm{c}}$ Means with a same superscript within a row are not different $(p>0.05), \mathrm{t}^{1}=$ trace.

Treatment $^{1}$ : RFC=regular-fat control (LK30); RFT=regular-fat treatment (L155+L167+L12); MFC=medium-fat control (LK30); MFT $=$ medium-fat treatment $(\mathrm{L} 155+\mathrm{L} 167+\mathrm{L} 12)$

content.

\section{Conclusion}

Although medium-fat fermented sausages $(\sim 15 \%$ fat $)$ reduced the drying time by $1 \mathrm{wk}$, as compared to the regular-fat counterpart, reduction of fat levels resulted in textural problems as compared to regular-fat ones. Since fermented sausages with selected mixed starter culture ( $L$. plantarum $\mathrm{L} 155+L$. plantarum L167 $+P$. damnosus L12) have similar physicochemical properties and functional properties to those with commercial starter culture, the selected mixed starter culture might be used as a new functional starter culture to replace the commercial starter culture (LK-30 plus).

\section{Acknowledgements}

This study was financially supported by Agricultural Research \& Development Program (ARPC 2005-0190).

\section{References}

1. AOAC (1995) Official Method of Analysis. $15^{\text {th }} \mathrm{ed}$, Associ- 
Table 6. Changes of volatile compounds in fermented sausages as affected by ripening time

\begin{tabular}{|c|c|c|c|c|c|c|}
\hline \multirow{2}{*}{ Compounds } & \multicolumn{6}{|c|}{ "Ripening time (days) (Relative area) } \\
\hline & 0 & 3 & 7 & 14 & 21 & SEM \\
\hline 3-hydroxy-2-butanone & 21.5 & 18.7 & 86.7 & 61.5 & 29.9 & 7.50 \\
\hline Hexanal & $32.7^{\mathrm{c}}$ & $36.5^{\mathrm{c}}$ & $44.9^{c}$ & $86.7^{b}$ & $129.0^{\mathrm{a}}$ & 11.68 \\
\hline 3-methyl-furan & $\mathrm{t}^{\mathrm{b}}$ & $5.7^{\mathrm{b}}$ & $38.8^{\mathrm{a}}$ & $35.1^{\mathrm{a}}$ & $31.0^{\mathrm{a}}$ & 5.33 \\
\hline 3-methyl-butanoic acid & 13.0 & $\mathrm{t}^{1}$ & 1.3 & 19.9 & 14.4 & 7.36 \\
\hline dimethyl trisulfide & 13.7 & 16.0 & 23.1 & 19.3 & 24.9 & 3.97 \\
\hline 2-pentyl-furan & $\mathrm{t}^{\mathrm{b}}$ & $2.0^{\mathrm{b}}$ & $2.50^{\mathrm{b}}$ & $4.4^{\mathrm{b}}$ & $15.4^{\mathrm{a}}$ & 1.62 \\
\hline$\gamma$-terpinene & $36.5^{\mathrm{b}}$ & $43.0^{\mathrm{b}}$ & $42.5^{b}$ & $46.0^{\mathrm{b}}$ & $66.7^{\mathrm{a}}$ & 3.65 \\
\hline hexanoic acid & $\mathrm{t}^{\mathrm{e}}$ & $3.1^{\mathrm{d}}$ & $5.9^{\mathrm{c}}$ & $7.5^{\mathrm{b}}$ & $13.8^{\mathrm{a}}$ & 0.49 \\
\hline 1-methyl-4-(1-methylethyl)-benzene & $\mathrm{t}$ & 23.6 & 4.2 & 6.2 & 11.3 & 9.00 \\
\hline $\mathrm{R}(+)$-limonen & $0.3^{\mathrm{c}}$ & $2.4^{\mathrm{bc}}$ & $2.7^{\mathrm{bc}}$ & $5.3^{\mathrm{b}}$ & $11.1^{\mathrm{a}}$ & 1.08 \\
\hline 1,3,5-cycloheptatriene & $\mathrm{t}$ & $\mathrm{t}$ & 4.7 & 3.9 & 4.5 & 1.94 \\
\hline 2-methoxy-phenol & $\mathrm{t}^{\mathrm{b}}$ & $\mathrm{t}^{\mathrm{b}}$ & $35.8^{\mathrm{a}}$ & $32.5^{\mathrm{a}}$ & $36.9^{\mathrm{a}}$ & 7.48 \\
\hline$\alpha$-terpinolene & $105.0^{\mathrm{d}}$ & $225.0^{\mathrm{bc}}$ & $201.0^{\mathrm{cd}}$ & $330.0^{\mathrm{ab}}$ & $351.0^{\mathrm{a}}$ & 38.37 \\
\hline Camphor & 74.2 & 101.0 & 64.5 & 88.2 & 108.0 & 20.40 \\
\hline 4-methyl-1-(1-methylethyl)-3-cyclohexen-1-ol & $0.2^{\mathrm{c}}$ & $9.1^{\mathrm{ab}}$ & $3.4^{\mathrm{bc}}$ & $9.1^{\mathrm{ab}}$ & $13.9^{\mathrm{a}}$ & 2.66 \\
\hline 2-methoxy-4-methyl-phenol & $4.3^{\mathrm{c}}$ & $13.6^{\mathrm{c}}$ & $25.8^{\mathrm{bc}}$ & $60.8^{\mathrm{ab}}$ & $77.2^{\mathrm{a}}$ & 13.59 \\
\hline 4-ethyl-2-methoxy-phenol & $2.8^{\mathrm{b}}$ & $1.9^{\mathrm{b}}$ & $26.2^{\mathrm{ab}}$ & $31.5^{\mathrm{a}}$ & $38.1^{\mathrm{a}}$ & 7.95 \\
\hline 1,3-benzodioxole-5-carboxaldehyde & $\mathrm{t}^{\mathrm{b}}$ & $\mathrm{t}^{\mathrm{b}}$ & $5.4^{\mathrm{ab}}$ & $7.6^{\mathrm{ab}}$ & $9.9^{\mathrm{a}}$ & 2.47 \\
\hline$\alpha$-copaene & $\mathrm{t}$ & 2.8 & 4.2 & 7.4 & 10.9 & 3.03 \\
\hline decanoic acid & 9.7 & 24.2 & 11.9 & 22.6 & 30.3 & 5.70 \\
\hline trans-caryophyllene & $18.9^{\mathrm{b}}$ & $79.0^{\mathrm{b}}$ & $98.0^{\mathrm{b}}$ & $209.0^{\mathrm{a}}$ & $223.0^{\mathrm{a}}$ & 32.51 \\
\hline 3,7-dimethyl-(E)-1,3,6-octatriene & $\mathrm{t}^{\mathrm{d}}$ & $3.5^{\mathrm{cd}}$ & $11.7^{\mathrm{bc}}$ & $20.5^{\mathrm{ab}}$ & $30.1^{\mathrm{a}}$ & 3.50 \\
\hline (E)-4-tridecen-6-yne & $49.2^{\mathrm{b}}$ & $139.0^{\mathrm{a}}$ & $130.0^{\mathrm{a}}$ & $105.0^{\mathrm{ab}}$ & $162.0^{\mathrm{a}}$ & 22.30 \\
\hline caryophyllene oxide & $5.9^{\mathrm{c}}$ & $19.0^{\mathrm{c}}$ & $25.6^{\mathrm{bc}}$ & $43.9^{\mathrm{ab}}$ & $47.2^{\mathrm{a}}$ & 7.12 \\
\hline 3,4-dimethyl-3-cyclohexen-1-carboxaldehyde & $4.8^{\mathrm{b}}$ & $20.0^{\mathrm{a}}$ & $21.9^{\mathrm{a}}$ & $22.6^{\mathrm{a}}$ & $20.7^{\mathrm{a}}$ & 2.43 \\
\hline 4,8,8-trimethylspiro[2.6]non-4,6-diene & 6.0 & 9.5 & 6.8 & 7.3 & 7.9 & 4.23 \\
\hline adamantane & $\mathrm{t}$ & 3.3 & 7.0 & 5.5 & 4.1 & 3.48 \\
\hline 3,4-dimethyl-pyridine & 14.9 & 26.3 & 44.5 & 46.2 & 26.7 & 9.21 \\
\hline$\beta$-citronellol & 1.6 & 1.5 & 2.6 & 1.9 & 1.2 & 0.99 \\
\hline tetradecanoic acid & $7.0^{\mathrm{b}}$ & $44.3^{\mathrm{ab}}$ & $61.4^{\mathrm{a}}$ & $95.2^{\mathrm{a}}$ & $91.9^{\mathrm{a}}$ & 15.41 \\
\hline tetradecanal & 170.0 & 159.0 & 240.0 & 108.0 & 130.0 & 47.35 \\
\hline octadecanal & 0.1 & 7.0 & 2.3 & 1.0 & 1.1 & 2.80 \\
\hline (E)-5-eicosene & $23.0^{\mathrm{b}}$ & $62.0^{\mathrm{ab}}$ & $121.0^{\mathrm{a}}$ & $126.0^{\mathrm{a}}$ & $124.0^{\mathrm{a}}$ & 24.05 \\
\hline 1-hexadecanol & 11.5 & 13.4 & 31.2 & 7.3 & 14.2 & 6.56 \\
\hline n-hexadecanoic acid & 23.5 & 12.8 & 26.6 & 8.5 & 15.3 & 7.27 \\
\hline
\end{tabular}

${ }^{\mathrm{a}-\mathrm{e}}$ Means with a same superscript within a row are not different $(p>0.05) . \mathrm{t}^{1}=$ trace.

ation of Official Analytical Chemists, Washington, D.C.

2. Campagnol, P. C. B., dos Santos, B. A., Wagner, R., Terra, N. N., and Pollonio, M. A. R. (2012) Amorphous cellulose gel as a fat substitute in fermented sausages. Meat Sci. 90, 36-42.

3. Chin, K. B., Ji, S. T., Seo, S. W., and Shin, H. K. (1991) Effect of PSE pork on physicochemical and microbiological properties of European style fermented sausages during ripening. Korean J. Food Sci. Technol. 23, 661-666.

4. Cushman, D. W. and Cheung, H. S. (1971) Spectrophotometric assay and properties of the angiotensin-converting enzyme of rabbit lung. Biochem. Pharmacol. 20, 1637-1648.

5. De Vries, M. C., Vaughan, E. E., Kleerebezem, M., and De Vos, Willem. (2006) Lactobacillus plantarum - Survial, functional and potential probiotic properties in the human intestinal tract. Int. J. Dairy 16, 1018-1028.
6. De Vuyst, L., Falony, G., and Leroy, F. (2008) Probiotics in fermented sausages. Meat Sci. 80, 75-78.

7. Erkkila, S., Suihko, M. L., Eerola, S., Petaja, E., and MattilaSandholm, T. (2001) Dry sausage fermented by Lactobacillus rhamnosus strains. Int. J. Food Microbiol. 64, 205-210.

8. Gilliland, S. E. and Walker, D. K. (1990) Factors to consider when selecting a culture of Lactobacillus acidophilus as a dietary adjunct to produce a hypocholesterolemic effect in humans. J. Dairy Sci. 73, 905-911.

9. Han, S. M., Kim, Y. J., Lee, H. C., Chin, K. B., and Oh, S. J. (2006) Screening of lactic acid bacteria as starter culture for making fermented sausage. Korean J. Food Sci. An. 26, 511516.

10. Heath, H. B. and Reineccius, G. (1986) Isolation of food flavours. In: Flavour chemistry and technology, eds. H. B. Health 
and G. Reineccius. New York: AVI pp. 6.

11. Kaban, G. and Kaya, M. (2006) Effect of starter culture on growth of Staphylococcus aureus in sucuk. Food Control 17, 797-801.

12. Kim, J. S. (2004) Changes of food consumption pattern in America. Korean J. Community Living Sci. 15, 115-125.

13. Kim, Y. J., Lee, H. C., Park, S. Y., Park, S. Y., Oh, S. J., and Chin, K. B. (2008) Utilization of probiotic starter cultures for the manufacture low-fat functional fermented sausages. Korean J. Food Sci. An. 28, 51-58.

14. Leclerc, P. L., Gauthier, S. F., Bachelard, H., Santure, M., and Roy, D. (2002) Antihypertensive activity of casein-enriched milk fermented by Lactobacillus helveticus. Int. Dairy J. 12, 995-1004.

15. Lorenzo, J. M. K. and Fransco, D. (2012) Fat effect on physicochemical, microbial and textural changes through the manufactured of dry-cured foal sausage lipolysis, proteolysis and sensory properties. Meat Sci. 92, 704-714.

16. Lorenzo, J. M., Bedia, M., and Banon, S. (2013). Relationship between flavor deterioration and the volatile compound profile of semi-ripened sausage. Meat Sci. 93, 614-620.

17. Lücke, F. K. (1985) Fermented sausages. In: Microbiology of fermented foods. 1st ed. Wood B. J. B., editor. London and New York: Elsevier Applied Science publishers. pp. 41-71.

18. Lücke, F. K. (2000) Utilization of microbes to process and preserve meat. Meat Sci. 56, 105-115.

19. Mendoza, E., Garcia, M. L., Casas, C., and Selgas, M. D. (2001) Inulin as fat substitute in low fat, dry fermented sausages. Meat Sci. 57, 387-393.

20. Muguerza, E., Fista, G., Ansorena, D., Astiasaran, I., and Bloukas, J. G. (2002) Effect of fat level and partial replacement of pork backfat with olive oil on processing and quality characteristics of fermented sausages. Meat Sci. 61, 397-404.

21. Muthukumarasamy, P. and Holley, R. A. (2007) Survival of Escherichia coli $\mathrm{O} 157: \mathrm{H} 7$ in dry fermented sausages containing micro-encapsulated probiotic lactic acid bacteria. Food Microbiol. 24, 82-88.

22. Olivares, A., Navarro, J. L., Salador, A., and Flores, M. (2009) Establishment of the contribution of volatile compounds of the aroma of fermented sausages at different stages of processing and storage. Food Chem. 115, 1464-1472.
23. Olivares, A., Navarro, J. L., Salador, A., and Flores, M. (2010) Sensory acceptability of slow fermented sausages based on fat content and ripening time. Meat Sci. 86, 251-257.

24. Olivares, A., Navarro, J. L., Salador, A., and Flores, M. (2011) Effect of fat content on aroma generation during processing of dry fermented sausages. Meat Sci. 87, 264-273.

25. Papadima, S. N. and Bloukas, J. G. (1999) Effect of fat level and storage conditions on quality characteristics of traditional Greek sausages. Meat Sci. 51, 103-113.

26. Papamanoli, E., Tzanetakis, N., Litopoulou-Tzanetaki, E., and Kotzekidou, P. (2003) Characterization of lactic acid bacteria isolated from a Greek dry-fermented sausage in respect of their technological and probiotic properties. Meat Sci. 65, 859-867.

27. Park, S. Y., Chin, K. B., and Yoo, S. S. (2005) Flavor compounds and physicochemical properties of low-fat functional sausages manufactured with chitosans during refrigerated storage. Korean J. Food Sci. An. 25, 285-294.

28. Park, Y. W., Kouassi, M. A., and Chin, K. B. (1991) Moisture, total fat and cholesterol in goat organ and muscle meat. J. Food Sci. 56, 1191-1193.

29. Pennacchia, C., Ercolini, D., Blaiotta, G., Pepe, O., Mauriello, G., and Villani, F. (2004) Selection of Lactobacillus strains from fermented sausages for their potential use as probiotics. Meat Sci. 67, 309-317.

30. Pereira, D. I. and Gibson, G. R. (2002) Cholesterol assimilation by lactic acid bacteria and bifidobacteria isolated from the human gut. Appl. Environ. Microbiol. 68, 4689-4693.

31. Ruiz-Capillas, C., Triki, M., Herrero, A. M., Rodriguez-Salas, L., and Jimenz-Colmenero, F. (2012) Konjac gel as pork backfat replacer in dry fermented sausages: Processing and quality characteristics. Meat Sci. 92, 144-150.

32. Searcy, R. L. and Bergquist, L. M. (1960) A new color reaction for the quantitation of serum cholesterol. Clin. Chem. Acta 5, 192-199.

33. Urso, R., Comi, G., and Cocolin, L. (2006) Ecology of lactic acid bacteria in Italian fermented sausages: isolation, identification and molecular characterization. Syst. Appl. Microbiol. 29, 671-680.

(Received 2014.2.28/Revised 2014.5.11/Accepted 2014.5.16) 